\title{
The Research on Generalized Regional "Resource Curse" in China's New Normal Stage
}

Xiaoliang Xu ${ }^{1 \mathrm{ac} *}$, Xuefen $\mathrm{Xu}^{1 \mathrm{~b}}$, Qian Chen ${ }^{\mathrm{a}}$, Ying Che ${ }^{\mathrm{a}}$

${ }^{1}$ Contributed equally to this article

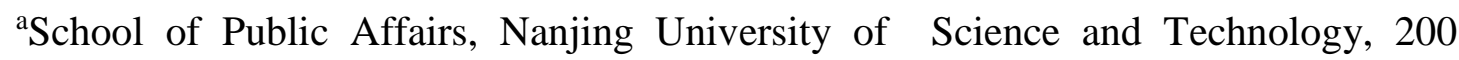

Xiaolingwei, Nanjing 210096, People's Republic of China

${ }^{\mathrm{b} S}$ Shool of Medicine, China Pharmaceutical University, Nanjing 210009, People's

Republic of China

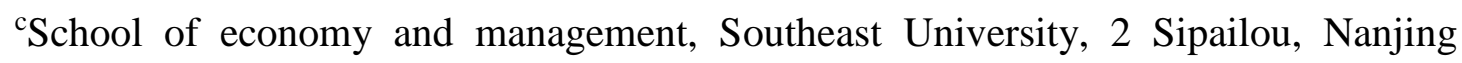
210094, People's Republic of China

* Corresponding authors:

Xiaoliang XU, Vice-professor, $\mathrm{PhD}$

School of Humanities and Social Sciences Nanjing University of Science and Technology, 200 Xiaolingwei, Nanjing 210094, China.

E-mail addresses: Xuxiaol2004@126.com 


\section{Abstract}

"Resource curse" phenomenon emerged as the greatest challenge for the social sustainable development in China's new normal stage. The paper looked into the changes of generalized regional "resource curse" with observations of data from 1998 to 2013 years by using a spatial dynamic panel data model; and the paper further explored the key factors and mechanism of generalized regional "resource curse" with Chinese northeast region as an example. The results showed: when considering the losses of resources using and environment pollution in social development, generalized "resource curse" did not exist in national level, but appeared in some regions such as Yellow River center region, northeast region and northwest region; and more complicated in Yangtze River center region and southwest region due to their specific conditions. Several important variables including resources and environment regulation policy, economy policy, regional location might be important factors. Regional location had a more significant impact on regional development, but if from a longer time latitude, increasingly stricter resources and environment regulation policy could make generalized regional "resource curse" less happen, but the impacts by regional location might be even more important.

Keywords Generalized regional "resource curse", Spatial dynamic panel data model, Chinese northeast region, China's new normal stage

\section{Introduction}

"Resource curse" is an interesting theory and happened frequently in some 
developing countries, which means there might be a negative relationship between nature resources and economy (Auty and Warhurst, 1993). Countries with abundant natural resource wealth have failed to perform better in economy those without. Since 1970 year, only few resource-rich countries' economic development reached the average degree of the world and most of them tended to grow slower than the countries without substantial resources. Some countries such as Norway, New Zealand and Australia broke through the dilemma of "resource curse" by excellent rule and system. Moreover, five countries of 82 countries belonged both to the top eight of natural capital wealth and to the top 15 of per capita income according to a World Bank study in 1994. Higher saving ratio, prudent macroeconomic and management policy, and public foundations were regarded as effective ways to avoid "resource curse". With the deterioration of resources and environment system, human beings faced the serious problem of environmental pollution and nature resources shortage. The conception of environmental protection and sustainable development is becoming a consensus, and researches on "resource curse" are more complicated and proved to be a hot academic topic.

Since 1991 year, "resource curse" effect has really appeared as a result of the negative significantly correlation between energy development and economic growth. Countries rich in natural resources constitute both growth losers and growth winners(Mehlum.et al,2006).And some researches indicated that "resource curse" theory also applied to regional economic growth in China on a long cycle(Hu and Xiao,2007), and if some key factors were hold, regional development discrepancy 
happened. With China entering the new normal stage, the quality of regional development is becoming a focus which importance has been recognized by central government and people from various classes. Generalized "resource curse" reflects the inner relationship between natural resources and the quality of national or regional economic development. There are two questions that remained to be resolved in generalized "resource curse" in Chinese new normal stage. One question is whether regional economy development has been accompanied by a sharp decreased quality of resources and environment system along with economy aims changes towards better energy-saving and less $\mathrm{CO}_{2}$ emissions. In other words, how will generalized regional "resource curse" change when considering the quality of regional economy with a potential cost of resource and environment system? The other question is what caused generalized regional "resource curse" happen in resource-rich regions.

Researches on the theory of "resource curse" have received a great deal of attentions. There were several causal relationships between the mechanism of "resource curse" and all kinds of variables. When economy development is being dependent excessively on nature resources, it is easy to extrude other elements, and result in crowding out effects(Dülger,2013; Bjorvatn,2013). Resource industries attracted a great deal of investments, squeezed other industrial development, and caused more human resources costs due to the rapid increased prices (Eisgruber,2013). In general, human resources, capital resources, regulation policy and regional location were regarded as significant factors to promote the regional development. Some research indicated the policy could curb China's total carbon emissions by improving 
energy structure (Tang, et al.,2015). At the same time, rent-seeking, corruption, lack of management capacity of regional government might be an explanation of regional "resource curse" in some countries or regions (Pegg, 2010). Rent-seeking might occur when the government earned considerable revenues from resources extraction directly, while the higher quality of regulation policy would in turn decrease the possibility of "rentier effects". In a similar way, many researches showed the crowding out effects of human resources and capital resources block regional economy of resource-rich regions. A demographic transition from the bonus of nature resources to rule might be exist based on different samples, which supported the theoretical predictions (Bjorvatn and Farzanegan,2013). However, the current emphasis on the quality of regulation policy as a potential solution of regional "resource curse" has largely been ignored(Stevens and Dietsch,2008). In fact, the crowding out effect of human resources was dampened or even reversed in countries with better institutions (Eduardo and Christian, 2011).

Recent studies about "resource curse" in China mainly focused on the impacts of economy. For example, previous research associated energy with resource development in minority regions (Chen et al.,2013). Relationships among resource and economy were tested, and low quality rule and lack of human resource was main reasons for lagging economy (Xu et al.,2006). An inverted U curve between economy and nature resources might be existed by total factor productivity (TFP) development due to resources development (Shao et al.,2014). And an empirical case study of mining areas was done to explore state responses to the curse of natural resources in 
China (Zeng et al.,2015). Meanwhile, the argument of Chinese "resource curse" is under way because of large size of lands and rich resources in different regions, especially in worsen environment. Considering the relationship between resources using and environment, "resource ecological curse" really existed in provinces level (Du et al.,2009), because of environment pollution and ecological damages in the processing of resources exploiting and using. In western regions of China, worse quality of the environment made the phenomenon of "resource curse" more serious than before (Feng et al,2007).However, there was little direct evidence that omitted geographical or climate variables explained "resource curse" (Sachs and Warner,2001). So, the impact of geographical conditions on growth was much more complexes especially in environment changing condition (Gallup et al., 1999).

Although the literature is extensive on Chinese economy and resources system, researches on the quality of regional development as well as series of related environmental problems are still lack in China. More importantly, because market mechanisms is weaker to correct the externalities caused by resource consumption, the quality of bureaucracy management, such as rule and regulations policy, could affect greatly the formation of unreasonable economy structure, as resource industries may gain the highest profits with easy way (Busse and Gröning,2013).If the regulation or rule was weaker, the structure of economy would not as likely be adjusted in resource-depended regions especially without considering the cost of resources and environment system. The industry composition in cross-country growth regressions was important (Alexander,2015). 
Generalized regional "resource curse" is essentially caused by resources and environmental pollution because of excessive resources using and exploitation. However, the study on generalized regional "resource curse" is mainly based on qualitative empirical analysis. Scholars believed that resources policy and rule improvement will change economic growth path and avoid the phenomenon of "resource curse" happen. Resources and environment regulation policy is particularly important as a useful tool to break out the dilemma of regional "resource curse". Correlation analysis of policy research on resources and environment provided effective references. But studies were still relatively few, which led to the ignorance of rule in guiding resource exploiting, using and consumption to break out generalized regional "resource curse".

The paper tried to looks into the relationships between regional economic quality and nature resources in the new normal stage of China. We used a spatial dynamic panel data model to analyze the distribution of generalized regional "resource curse" with panel data of 1998-2013 years. And then we used northeast region of China to explore the inner mechanism of generalized regional "resource curse".

The paper is organized as follows: Section 2 built a spatial dynamic panel data model and made the basic data. Section 3 tested and discussed the empirical results. Section 4 took northeast region in China as an example to find out the mechanism of generalized regional "resource curse", followed by main conclusions in Section 5.

\section{Model and data}

\section{1 Model}


Because spatial econometrics could deal with interaction effects among different geographical units effectively, the spatial dynamic panel data model was be used to explain relationships between the behavior of agents and performance in development. The spatial dynamic panel data model was adopted to verify the theory of "resource curse" from the level of a single country or regions. The data model was based on maximum likelihood (ML), quasi maximum likelihood (QML), generalized method of moments (IV/GMM), or the Bayesian Markov Chain Monte Carlo (MCMC) approach (Anselin,1988; Lee,2004;Kelejian and Prucha,1998, and LeSage,2009).A bias corrected estimator construct for a dynamic model with spatial fixed effects(Yu et al.,2008). Time-period fixed effects were extended (Lee and Yu ,2010) and firstly estimated the model by the ML estimator developed for the spatial lag model with spatial fixed effects (Elhorst, 2003). The model contained data from different dimensions and its advantages lied in capturing the dynamic adjustment process of individual differences, so as to effectively reduce the bias by the summed data. Although the advantage of structural breakout has the potential impact to reflect the relationship between natural resources and economic development, the spatial dynamic panel data model can control the endogenous variables by high degree of freedom and lower collinearity data, such as regulation policy, environment pollution and so on. So, the spatial dynamic panel data model could be used to estimate the relationships between the quality of national or regional development and nature resources. The factors including regional natural resource endowments, capital resources, human resources, resources and environment regulation policy, regional 
location, regional economy policy and regional development quality are assumed among all switches from generalized regional "resource curse" to the sustainable development. There are two steps in this paper by using the spatial dynamic panel data model, and the first step is to validate the existence of generalized regional "resource curse" based on national or regional data; the second step is to explore the mechanism and find out the key factors in the mechanism of generalized regional "resource curse".

Now we turn to the technical details of the spatial dynamic panel data model. The spatial dynamic panel data model is given by

$$
Y_{i t}=\alpha_{0}+\alpha_{1} \sum_{n=1}^{3} R_{n i t}+\alpha_{2} \min i n g_{i t}+\alpha_{3} \text { non }-\min i n g_{i t}+\alpha_{4} R E G_{i t}+\alpha_{5} E P_{i t}+\alpha_{6} L+U_{i}+\varepsilon_{i t}
$$

Where, $Y$ denotes the quality of regional economic development, $R$ denotes regional resources input, min ing denotes mining industry input, non-min ing denotes non-mining industry input, $R E G$ denotes resources and environment regulation, $E P$ denotes regional economy policy, $L$ denotes regional location, $U$ denotes the deviation within a fixed time-series among different regions, $\varepsilon$ denotes random disturbance, $\alpha_{0} 、 \alpha_{1} 、 \alpha_{2}, \alpha_{3}, \alpha_{4}, \alpha_{5}$ and $\alpha_{6}$ denote corresponding coefficient vector, $n$ denotes different kinds of resources, $i$ denotes regional panel data, $t$ denotes the time.

Due to the substitution relationships among natural resources, capital resources and human resources, we need to estimate all these variables respectively, and the equations of linear regression are as following:

$$
Y_{i t}=\beta_{i}+A R \min \text { ing }_{i t}+\text { BRnon }-\min i n g_{i t}+C R d_{i t}+D P_{i t}+U_{i}+\varepsilon_{i t}
$$




$$
\begin{aligned}
& Y_{i t}=\beta_{i}+A K \min \text { ing }_{i t}+\text { BKnon }-\min \text { ing }_{i t}+C R d_{i t}+D P_{i t}+U_{i}+\varepsilon_{i t} \\
& Y_{i t}=\beta_{i}+A H \min \text { ing }_{i t}+\text { BHnon }-\min \text { ing }_{i t}+K R d_{i t}+D P_{i t}+U_{i}+\varepsilon_{i t}
\end{aligned}
$$

Where, $Y$ denotes regional economic development, $R$ denotes regional resources input, $K$ denotes regional capital input, $H$ denotes regional human resources input, min ing denotes mining industry input, non-min ing denotes non-mining industry input, $P$ is policy, $U$ denotes deviation within a fixed time-series among different regions, $\varepsilon$ denotes random disturbance.

Although many indexes can be available for quantifying regional development, most of them are either to be restricted by theoretic hypothesis or do not evaluate fairly and effectively. In order to appraise the quality of regional economic development, we adopt the index of economic green development by taking the cost of resources and environment pollutions into account. The equation of the quality of national or regional economic development is as following:

$$
Y_{i t}=\frac{G D P_{i t}-G D P_{i(t-1)}}{G D P_{i t}}\left(1-r_{i t}\right) \times 100 \%
$$

Where, $Y$ denotes the quality of national or regional development, GDP denotes gross domestic production, $r$ denotes the rate of resources and environment cost, $i$ denotes the number of regions, $t$ denotes the time.

Meanwhile, we use the index of national or regional development to evaluate the deviation between regional development and resource endowments. The equation of the index of quality of national or regional development is given by:

$$
\mathrm{RI}=\frac{\mathrm{Ri} / \Sigma \mathrm{Ri}}{\mathrm{GDPi} / \Sigma \mathrm{GDPi}}(1-r)
$$


Where, RI denotes the index of quality of national or regional development, R denotes the energy production, $G D P$ denotes gross domestic production, $r$ denotes the rate of resources and environment cost, $i$ denotes the number of different regions.

\section{2 Data}

As to the parameters, the paper selects regional natural resources, capital, human resources, resources and the environment regulation policy, economy policy, and regional location (see table 1). The parameters include the parameter of regional natural resources, the parameter of capital resources, the parameter of human resources, the parameter of resources and environment regulation policy, regional economy policy and the parameter of regional location.

According to "Regional coordinate development strategies and policies" by State Department of China, the paper divides China into eight regions which are Yellow river center region, Yangtze River center region, northeast region, north coastal region, east coastal region, south coastal region, southwest region and northwest region respectively, as showed in table 2 . We obtain the correlation coefficient between regional economic development and nature resource endowments as following table 3.

Panel data included 6 units of time series, and 330 samples from 1998 to 2013 year, which was calculated from the China statistical yearbook and provinces statistical yearbook. Through the analysis of correlation coefficients, we got variables collinearity conditions in model, as showed in table 4 and 5. 


\section{Test results}

The spatial dynamic panel data model adopts generalized least square method to evaluate the results. With controlled variables increased, the estimated correlation coefficients were not changed significantly, and so $\mathrm{R}^{2}$ testing has been passed, which proved that the second-order interference terms did not exist in dynamic panel data, and the robustness of estimated model is credible. We run the spatial dynamic panel data model and got the results. As China has vast land and is rich in natural resources, the economy and social development is different greatly in provinces or regions. Considering the impacts by key factors in different regions, it is obvious to test the phenomenon of generalized regional "resource curse" from different points. And the paper focuses on the probability of generalized "resource curse" from the national level, regional level and time level, respectively.

1) The analysis of generalized "resource curse" from the national level

The price of nature resources has been gradually adjusted and controlled by the market mechanism, and the value of resources property is mainly reflected by the market prices. While the prices of coal, oil and other nature resources have risen greatly than the past, resource-rich regions could get bonus through nature resources exploiting and sales; and regional economy has grown rapidly and further promoted national economic development. When variable $\mathrm{R}$ was the only factor taken into account, its estimated value was positive. The significance test of 5\% showed generalized regional "resource curse" phenomenon in national level seemed not be established (see table 6). 
However, it was not enough to certify the existence of generalized "resource curse" phenomenon in regional level, and we needed to further explore the relationships after controlling other variables. Apart from variable R, variables $\mathrm{H}, \mathrm{K}$, REG,EP and L were likely to have an impact on the regional development. The variable $\mathrm{H}$ and $\mathrm{K}$ denote labor and capital resources factors, which the estimated value were positive and this also meant that capital and labor resources inputs played a stimulating role in promoting national economic growth. The variable REG denoted resource and environmental regulation policy, which estimated value was negative, and the reason might be lied in that stricter resource and environmental regulation policy would increase the costs of nature resources exploiting and using in social and economy transaction, especially on some regions with developed resource-intensive manufacturing industries. Importantly, resources and environment regulation policy would directly affect economic growth rate. The variable L donated regional position, which estimated value was positive, indicating that the role of the regional position on economic growth was a significant positive correlation.

Although generalized "resource curse" phenomenon did not exist in national level, it simply could not effectively explain the increasing regional gaps in economy. It was more persuasive to test the existence of generalized regional "resource curse" phenomenon from the view of regional level.

2)The analysis of generalized regional "resource curse" in different regions In the results, the phenomenon of generalized regional "resource curse" appeared differently in China. The estimated coefficients of resources variable on Yellow River 
center region, northeast region and northwest region were negative, which indicated that generalized regional "resource curse" existed in the relevant areas. The quality of relative regional development also verified the existence of generalized regional "resource curse", which was shown in table 7.

Resource variables in northern coastal region were positive, indicating that there was no phenomenon of generalized regional "resource curse" in relevant regions, and the quality of regional development was positive. Resource variable in Yangtze River center region and southwest region were proved to be more complex cases; and Resource variables in other regions included four positive values, and two negative value. Resources and environmental regulation policy, regional economy and location variable have played a negative impact on regional economic grow, and the role of regional growth resources could not be effectively judged. Meanwhile, regional development quality coefficient which was a smaller positive number was proved to play a weaker supporting role in the relevant regional growth by nature resource endowments. Conclusive evidences on the quality of regional development by previous studies could be attributed to the competitive market mechanism. The results in our model provided a new choice to understand generalized regional "resource curse" from a dynamic viewpoint. So, it was more meaningful to explore the inner dynamic response relationship between resources endowments and regional economic growth from the point of different time periods.

3)The analysis of generalized regional "resource curse" in different time periods General speaking, resources variable $\mathrm{R}$ was positive in the two time periods 
(1998 - 2003 year and 2009 - 2013 year), and nature resources endowments played an active role in promoting regional growth. In 2004 - 2008 time periods, Resource variables $\mathrm{R}$ was a smaller negative number, which indicated that in past five years, nature resources could not promote the regional development effectively(see table 8).

Variables REG showed that the relationship between the severity of resources and environment regulation policy and economic growth was still divergence. The main reason might be a greater inconsistency between China's current irrational economic structure and increasingly stricter resources and environment policy. From the point of variable L, the role regional economic development played was still important obviously. Resource variables in Yellow River center region, northwest region and northeast region at different time periods were negative, which meant regional resource endowments were not able to effectively promote local economic development, and generalized regional "resource curse" phenomenon appeared in relative regions. Resource variables were negative in Yangtze River center region and southwestern region in 1998-2003 year and 2004 -2009 year, which were as following in table 9 .

In 1998-2003 year, there was a divergence between natural resources and regional economic growth in Yellow River center region, Yangtze River center region, northeast region, southwest region and northwest region. Because capital and labor resources inputs were excessively concentrated in resources industries, low resources prices led to a prolonged slump in the relevant regional development. While in 2003-2013 year, with the adjustment of resources and environment policy, nature 
resource-rich areas were also benefit from higher resource prices, and generalized regional "resource curse" gradually reduced.

\section{The analysis of mechanisms of generalized regional "resource curse"}

Now, we turned to the mechanisms of generalized regional "resource curse" with the example of Chinese northeast region which was troubled with bad economy and poor environment in recent years.

According to the results, there were relationship between variables and the resource-rich degree, which could be used to explore the transmission mechanism of generalized regional "resource curse". So we established linear equations (Papyrakis and Gerlagh,2007), which was as following.

$$
Z_{i t}=f\left(R E G_{i t}, E P_{i t}, L\right)=\beta_{0}+\beta_{1} R_{i t}+U_{i}
$$

Where, $Z$ denotes the sum of regional location, resource and environment regulation policy, and economy policy; $R$ denotes regional resources input, $R E G$ denotes resources and environment regulation, $E P$ denotes economy policy, $L$ denotes regional location, $U$ denotes deviation within a fixed time-series in different regions.

Based on panel data of Chinese northeast region from 1998 to 2013 year, we got the regression results which were as following by table 10.Negative correlation within all variables can be remarkably observed in regression results which indicated generalized regional "resource curse" in Chinese northeast region might be induced by these key factors. In the mechanism of generalized regional "resource curse", policy played an important role in controlling the regional economy development 
under the conditions of low costs of resource and environment in resource-rich regions. With the regulation of resource and environment stringent, there has been a sharp increase in the quality of regional development. However, the economy of Chinese northeast region reliance on heavy industries has become dim no matter scale or quality, especially in 2009-2013 years. Whereas, regional location also has a negative impact on economy development of northeast region, which should be not only the potential for improving regional development, but a significant factor to perfect the rule of nature resources exploit and using.

Meanwhile, regional location played a more important role in mechanism of generalized regional "resource curse", where the proportion is nearly triple than resource and environment regulation policy. Since opening up and reform of China, external economic and social environmental of the relative areas has undergone rapid changes and led to excess capacity of production especially in northeast region(see table 11).

The dynamic response relationship in Chinese resources and economic growth has been in the context of greater volatility. For example, economic growth rate of Liaoning province, Heilongiiang province and Jilin province was only $1.9 \%, 4.8 \%$ and 5.8\% in 2015,respectively; and generalized regional "resource curse" phenomenon became worse than before. During the same period, domestic and international environment might be a major cause of unrest which led to generalized region "resource curse". Because huge of funds precipitated in resource industry, which squeezed the scale of investment in manufacturing sector, and led to atrophy of 
other local industries, irrational industrial structure further deteriorated the quality of environment system. Meanwhile external funding is difficult to enter the related industries, since accumulated funds by resource industries are lack of investment channels. Excess capacity of production in Chinese resource industries forced local investors out and a large number of capitals spurred an exoduses.

Meanwhile, the dominance of resources industries in relative areas, and loose resources and environment policy led to the loss of financial and human capital resources. According to statistics year of 2013, capital outflow rate in Chinese northeast region was nearly $10 \%$, while the average annual net outflow of population was about 2 million. With respect to some developed regions, excessive funds concentration on resource industries in regional development made resources industries dominant, and induced other industries gradually shrink. So when resource policy was tightened, it directly led to a vicious cycle of accumulation of capital outflow, and forced investors to transfer to other areas. During the same time, upgrading the technical level in heavy industries required a lot of capital investment. Resources and environment policy stimulated the investment of resources industry, triggered a tremendous negative impact on financial and human capital elements and made regional economic growth lag due to lack of innovation.

Meanwhile, unreasonable property rights rule resulted in a low innovation capability. There was an inner deficiency in the resources industrial property rule because of special conditions in China. And it was mainly difficult to effectively define the ownership, management rights, the right to use and beneficial interest. The 
ownership of resource industries belonged to the country in law, local government and resource management departments was to implement management rights, and interests of nature resources belonged to the state. The dual properties of the resource property right system allowed local governments to obtain resources dividend with easy way, and management utilization of resource industries were to seek their own interests, which were captured by interest groups or corrupted. This state capture behavior may solidify unreasonable old property rights system, and further strengthen non-exclusive resources. So a large number of rent-seeking activities led to low regional innovation capacity, and seriously damage regional sustainable development.

\section{Conclusions and policy implications}

With economy rapid increasing, the quality of regional development is becoming a hot topic in Chinese new normal stage. Generalized regional "resource curse" is attracting the interesting of academic study especially in China with abundance resource and different regional development level. The paper built a spatial dynamic panel data model with empirical data of 1998-2013 year to analyze the existence of generalized regional "resource curse" with consideration of the costs of resource and environment. Meanwhile we took northeast region of China as an example to analyze the special causes of generalized regional "resource curse", and tried to find out an effective way to narrow regional gap and reduce regional "resource curse".

The results showed: after controlling other variables, the hypothesis of generalized regional "resource curse" was also verified, which meant generalized 
regional "resource curse" did not happen in China from a national level by $5 \%$ significance test of variable R. However, it simply could not effectively explain the increasing regional differences. So it was more persuasive for generalized regional "resource curse" phenomenon from a regional level. The tested results proved that there was negative relationship between nature resources and the quality of regional development if taking into account the loss of resources and the environment; and generalized regional "resource curse" phenomenon exactly existed in new normal stage of China. Meanwhile, the regional distributions of "resource curse" were different from before greatly. Generalized regional "resource curse" of Yellow River region, northeast region and northwest region existed, while not happened in northern coastal region. And resource variable in Yangtze River center region and southwest region was more complex; and resource variable in other regions included four positive values, and two negative values, which indicated generalized regional "resource curse" may appear in different time. At different time periods, resource variables in Yellow River center region, northwest region and northeast region are negative. In detailed, there was a divergence between natural resources and regional economic growth in Yellow River center region, Yangtze River center region, northeast region, southwest region and northwest region in 1998-2003 year; but in 2003-2013 year, generalized regional "resource curse" gradually reduced. In the mechanism of generalized regional "resource curse", resources and environment regulation, regional economy policy and regional location have important impacts, where regional location played a more significant role than others, and from time 
latitude point, servant resources and environment regulation would accelerate the influence and improve the quality of regional development.

Therefore, the key factors such as the quality of important mineral resources policy in mechanism of generalized regional "resource curse" in China are better ways to adjustment resources exploit and using and alleviate generalized regional "resource curse". Due to different effects by resource policy, the government could design and select stricter resource and environment policy based on social development in different regions with characteristics of resource endowments, combined with generalized regional "resource curse" condition.

To improve sustainable development of Chinese society, we gave some policy implications as following: 1) Accelerate resource policy reforms to improve the quality of important mineral resources policy such as resource tax, resource subsidy and price mechanism, so that designed resources policy can play a more important role in regulating the production and behaviors of resources using. Because of the different impacts on regional development by resource policy, the center government should make resources policy based on different characteristics of regional socio-economic development and natural resources endowments, combined with generalized regional "resource curse" case. Under the circumstances, different and characterized resource policy design in China will be better for alleviating the phenomenon of generalized regional "resource curse". For example, the center government could adopt restricted resource regulated policy in some serious generalized "resource curse" regions such as Yellow River region, northeast region 
and northwest region in china.2) As far as the distribution of generalized "resource curse" regions, the government should effectively change the development mode through tax reform, resources and environment regulation policy, and economy policy adjustment. The regulation and policy must consist of the content of socio-economic factors, regional differences and sustainable development to gradually reduce the incidence of "resource curse" situation by the technological improvement of related industries.3) The government should focus on the coordination of economy, resource and environment policies and regulation and further expand the depth of policy design. In generalized "resource curse" region, the positive policy and less regulation of the government is a necessary step for the changes of the mainly industries relied on nature resources.4) Regional innovation capacity should be developed as a useful way to alleviate the phenomena of generalized regional "resource curse". The further adjustment of the structure of industries is needed accompany with the improvement of regional innovation capacity. At this case, the government must make effective economic and management policy to incentive the innovation capacity in different regions of generalized "resource curse".

\section{Acknowledgements}

The authors gratefully acknowledge the financial support by Chinese National Science Foundation of China (Grant No.71203002), The Postdoctoral Science Foundation of China(Grant Nos.2013M540398 and 2015T80472), Minister of Education Social Science Foundation(Grant No. 12YJ81006), Jiangsu Province Social 
Science Foundation(Grant Nos.13WTB030 and 15SSL051), the Fundamental Research Funds for the Central Universities(Grant Nos. 30915013115 and AE15001_02), Jiangsu Province Social Science Research Quality Work(Grant No. 15SYB-006), 2012I-0Project(IO12-ZC46), "Star of Zijin" of "Program for Young Principal Investigators" of Nanjing University of Science and Technology and Base of Service-oriented Government Construction Research of Jiangsu Province(Grant No.15SSL051).

\section{References:}

Auty, R., Warhurst, A.,1993. Sustainable development in mineral exporting economies. Resources Policy19, 14-29.

Xu, K., Wang, J., 2006. An empirical study of a linkage between natural resource abundance and economic development. Economy Research Journal, 78-89.

Shao, S., Yang, L., 2014. Natural resource dependence, human capital accumulation, and economic growth: A combined explanation for the resource curse and the resource blessing. Energy Policy74, 632-642.

Dülger, F., Lopcu, K., Burgaç, A., \& Ball1, E.,2013. Is Russia suffering from Dutch Disease? Cointegration with structural break. Resources Policy38, 605-612.

Bjorvatn, K., Farzanegan, M. R. ,2013. Demographic transition in resource rich countries: a blessing or a curse?. World Development45, 337-351.

Eisgruber, L.,2013. The resource curse: Analysis of the applicability to the large-scale export of electricity from renewable resources. Energy Policy57, 429-440. 
Pegg, S., 2010. Is there a Dutch disease in Botswana? Resources Policy 35, 14-19.

Stevens, P., Dietsche, E. ,2008. Resource curse: An analysis of causes, experiences and possible ways forward. Energy Policy36, 56-65.

Cavallo, E., Daude, C. ,2011. Public investment in developing countries: A blessing or a curse?. Journal of Comparative Economics39, 65-81.

Busse, M., Gröning, S.,2013. The resource curse revisited: governance and natural resources. Public Choice154, 1-20.

World Bank.,1994. Expanding the measure of wealth: indicators of environmentally sustainable development, Environmentally Sustainable Development Studies and Monographs series No. 7.

Mehlum, H., Moene, K., Torvik, R.,2006. Institutions and the resource curse. The Economic Journal116, 1-20.

Hu.Y, Xu. D.,2007. The threshold of economic growth and the natural resource curse. Management World4, 15-23.

Tang. L., Shi. J., Yu, L., Bao, Q. ,2015. Economic and environmental influences of coal resource tax in China: A dynamic computable general equilibrium approach. Resources, Conservation and Recycling(In press).

Zeng, M., Zhan, J. V. ,2015. Sharing resource wealth for peace: A Chinese strategy to cope with the resource curse. The Extractive Industries and Society2, 302-309.

James, A. ,2015. The resource curse: A statistical mirage? Journal of Development Economics114, 55-63.

Papyrakis, E., Reyer G.,2007. Resource abundance and economic growth in the 
United States. European Economic Review 51: 1011-1039.

Anselin, L., 1988. Spatial econometrics: Methods and models. Kluwer, Dordrecht.

Lee, LF., 2004.Asymptotic distribution of quasi-maximum likelihood estimators for spatial autoregressive models. Econometrica72:1899-1925.

Kelejian, HH., Prucha, IR., 1998. A generalized spatial two stage least squares procedure for estimating a spatial autoregressive model with autoregressive disturbances. Journal of Real Estate Finance and Economics 17(1):99-121.

LeSage,JP., Pace, RK., 2009. Introduction to spatial econometrics. CRC Press Taylor \& Francis Group, Boca Raton.

Yu, J.,Jong, R. de., Lee ,LF., 2008, Quasi-maximum likelihood estimators for spatial dynamic panel data with fixed effects when both $\mathrm{n}$ and $\mathrm{T}$ are large. Journal of Econometrics 146:118-134.

Lee. L.F., Yu. J., 2010, A spatial dynamic panel data model with both time and individual fixed effects. Econometric Theory 26:564-59.

Elhorst,J,P., 2003, Specification and estimation of spatial panel data models. International Regional Science Review26:244-268.

Du. K,Zhou. Q,Cai. Y.,2009, Abundant natural resources, environmental regulation failure and "ecological curse", Economic geography 2:290-297.

Feng. Z, Yu. L, Yu. W., 2007,Caution of resource curse and solution of thorny problem of development of resources in western China. Journal of Xi' an jiao tong university (social sciences)2:7-17.

Jeffrey D. Sachs, Andrew M. Warner.,2001, Natural resources and economic 
development the curse of natural resources, European economic review 45: 827-838.

Gylfason, T., Herbertsson, T.T., Zoega, G., 1999. A mixed blessing: Natural resources and economic growth. Macroeconomic Dynamics 3, 204-225. 
Table 1 The parameters of the spatial dynamic panel data model

\begin{tabular}{ll}
\hline \multicolumn{1}{c}{ The parameters } & \multicolumn{1}{c}{ Indexes } \\
\hline $\begin{array}{l}\text { the parameter of region's resource endowment } \\
\text { the parameter of capital resources }\end{array}$ & $\begin{array}{l}\text { employees of resources industry and total employment ratio } \\
\text { regional fixed-asset investment } \\
\text { the proportion of the region's total output } \\
\text { employment share of the total number of regions }\end{array}$ \\
$\begin{array}{ll}\text { the parameter of human resources } \\
\text { the parameter of resources and environment }\end{array}$ & $\begin{array}{l}\text { regional economy policy } \\
\text { the parameter of regulation policy } \\
\text { the parameter of regional location }\end{array}$ \\
\hline
\end{tabular}

Table 2 The province distribution within different regions

\begin{tabular}{lllll}
\hline \multirow{2}{*}{ Regions } & $\begin{array}{l}\text { Yellow river } \\
\text { center region }\end{array}$ & $\begin{array}{l}\text { Yangtze River } \\
\text { center region }\end{array}$ & $\begin{array}{l}\text { Northeast } \\
\text { region }\end{array}$ & $\begin{array}{l}\text { North } \\
\text { coastal region }\end{array}$ \\
\hline \multirow{2}{*}{ Provinces } & Shaanxi、Shanxi、 & Hubei、Hunan、 & Liaoning、iling & Beijing、Hebei、 \\
& Henan、Inner Mongolia & Jiangxi、Anhui & 、Heilongjiang & Tianjing、Shandong \\
\hline \multirow{2}{*}{ Regions } & East & South & Southwest & Northwest \\
& coastal region & coastal region & region & region \\
\hline \multirow{2}{*}{ Provinces } & Shanghai、 & Guangdong、Fujian & Yunnan、Guizhou、 & Gansu、Qinhai、 \\
& Zhejiang、Jiansu & Sichuang、 Hainan & Chongqin、Guangxi & Xinjiang \\
\hline
\end{tabular}

Table 3 The correlation coefficient between regional development and resource endowments (2012)

\begin{tabular}{lcccc}
\hline & $\begin{array}{c}\text { Yellow river } \\
\text { center } \\
\text { region }\end{array}$ & $\begin{array}{c}\text { Yangtze River } \\
\text { center region }\end{array}$ & $\begin{array}{c}\text { Northeast } \\
\text { region }\end{array}$ & $\begin{array}{c}\text { North } \\
\text { coastal region }\end{array}$ \\
\hline GDP (hundred million RMB) & 61616 & 65631 & 47323 & 97665 \\
GDP ration & $11.41 \%$ & $12.15 \%$ & $8.76 \%$ & $18.08 \%$ \\
Pollution (hundred million RMB) & 1203 & 1166 & 1122 & 528 \\
Pollution ration & $0.22 \%$ & $0.22 \%$ & $0.21 \%$ & $0.10 \%$ \\
energy increase ration & $22.27 \%$ & $25.16 \%$ & $19.82 \%$ & $21.37 \%$ \\
RI & 1.9475 & 2.0662 & 2.2578 & 1.1808 \\
\hline & East & South & Southwest & Northwest \\
& coastal region & coastal region & region & region \\
\hline GDP (hundred million RMB) & 113764 & 81276 & 56841 & 15935 \\
GDP ration & $21.07 \%$ & $15.05 \%$ & $10.53 \%$ & $2.95 \%$ \\
Pollution (hundred million RMB) & 1231 & 757 & 1724 & 459 \\
Pollution ration & $0.23 \%$ & $0.14 \%$ & $0.32 \%$ & $0.08 \%$ \\
energy increase ration & $12.52 \%$ & $13.73 \%$ & $13.58 \%$ & $10.76 \%$ \\
RI & 0.5928 & 0.9110 & 1.2855 & 3.6445 \\
\hline
\end{tabular}


Table 4 The descriptive statistics of variable in model (1998-2013)

\begin{tabular}{cccccc}
\hline Variable & Observations & Average & Deviation & Min & Max \\
\hline GDP & 330 & 9.29 & 7.9 & 7.7 & 11.9 \\
R & 330 & 0.41 & 0.52 & 0 & 0.66 \\
K & 330 & 0.22 & 0.18 & 0.03 & 0.85 \\
H & 330 & 0.39 & 0.23 & 0.07 & 0.44 \\
REG & 330 & 0.36 & 0.44 & 0 & 1 \\
EP & 330 & 0.27 & 0.39 & 0 & 1 \\
L & 330 & 0.22 & 0.31 & 0 & 1 \\
\hline
\end{tabular}

Table 5 The correlation of variable in model (1998-2013)

\begin{tabular}{cccccccc}
\hline Variable & GDP & R & K & H & REG & EP & L \\
\hline GDP & 1.0000 & & & & & & \\
R & 0.2527 & 1.0000 & & & & & \\
K & 0.1732 & 0.2361 & 1.0000 & & & & \\
H & 0.1529 & 0.2837 & 0.2664 & 1.0000 & & & \\
REG & 0.2126 & 0.3246 & 0.2884 & 0.2217 & 1.0000 & & \\
EP & 0.2452 & 0.3627 & 0.3216 & 0.3238 & 0.3571 & 1.0000 & \\
L & 0.3734 & 0.1762 & 0.4326 & 0.2265 & 0.1524 & 0.1524 & 1.0000 \\
\hline
\end{tabular}

Table 6 Generalized "resource curse" in country's overall level

\begin{tabular}{|c|c|c|c|c|c|c|}
\hline GGDP & (1) & (2) & (3) & (4) & (5) & $(6)$ \\
\hline \multirow{2}{*}{$\mathrm{R}$} & 5.47 & 4.69 & 4.23 & 4.47 & 4.83 & 4.56 \\
\hline & (1.35) & (1.12) & (1.16) & (1.08) & $(1.24)$ & (1.12) \\
\hline \multirow{2}{*}{$\mathrm{K}$} & & 3.84 & 3.42 & 3.28 & 3.05 & 3.12 \\
\hline & & (1.07) & (1.27) & (1.15) & (1.12) & (1.21) \\
\hline \multirow{2}{*}{$\mathrm{H}$} & & & 6.89 & 6.36 & 6.14 & 6.07 \\
\hline & & & $(2.52)$ & $(2.27)$ & (2.14) & (2.03) \\
\hline \multirow{2}{*}{$\mathrm{RP}$} & & & & -3.82 & -3.68 & -3.45 \\
\hline & & & & $(-2.45)$ & $(-2.29)$ & $(-2.21)$ \\
\hline \multirow{2}{*}{$\mathrm{EP}$} & & & & & -2.45 & -2.36 \\
\hline & & & & & $(-2.11)$ & $(-2.03)$ \\
\hline \multirow{2}{*}{$\mathrm{L}$} & & & & & & -3.41 \\
\hline & & & & & & $(-.12)$ \\
\hline \multirow{2}{*}{ Constant } & 12.5 & 13 & 11.6 & 12.2 & 13.25 & 13.64 \\
\hline & (10.76) & $(9.5)$ & (8.95) & (7.85) & $(6.72)$ & $(6.85)$ \\
\hline $\begin{array}{c}\text { Observation } \\
\mathrm{s}\end{array}$ & 330 & 330 & 330 & 330 & 330 & 330 \\
\hline $\mathrm{R} 2$ & 0.008 & 0.015 & 0.13 & 0.25 & 0.32 & 0.32 \\
\hline
\end{tabular}


Table 7 The test of generalized regional "resource curse"

\begin{tabular}{lccccccc}
\hline & $(\mathbf{1})$ & $\mathbf{( 2 )}$ & $\mathbf{( 3 )}$ & $\mathbf{( 4 )}$ & $\mathbf{( 5 )}$ & $\mathbf{( 6 )}$ & RI \\
\hline Yellow river center region & -0.019 & -0.023 & -0.105 & -0.82 & -0.95 & -0.888 & 1.9475 \\
Yangtze River center region & 0.171 & 0.242 & 0.162 & -0.139 & -0.165 & -0.174 & 2.0662 \\
Northeast region & -0.038 & -0.052 & -0.124 & -0.149 & -0.138 & -0.142 & 2.2578 \\
North coastal region & 0.377 & 0.426 & 0.461 & 0.539 & 0.562 & 0.548 & 1.1808 \\
East coastal region & 0.434 & 0.485 & 0.496 & 0.628 & 0.647 & 0.629 & 0.5928 \\
South coastal region & 0.488 & 0.561 & 0.459 & 0.668 & 0.691 & 0.679 & 0.9110 \\
Southwest region & 0.243 & 0.267 & 0.273 & -0.194 & -0.178 & -0.184 & 1.2855 \\
Northwest region & -0.127 & -0.135 & -0.158 & -0.152 & -0.124 & -0.143 & 3.6445 \\
\hline
\end{tabular}

Table 8 Test of generalized regional "resource curse"

\begin{tabular}{cccc}
\hline & $\mathbf{1 9 9 8 - 2 0 0 3}$ & $\mathbf{2 0 0 4 - 2 0 0 8}$ & $\mathbf{2 0 0 9 - 2 0 1 3}$ \\
\hline \multirow{2}{*}{$\mathrm{R}$} & 4.66 & -0.28 & 2.18 \\
& $(1.21)$ & $(-0.15)$ & $(1.04)$ \\
$\mathrm{K}$ & 3.38 & 3.13 & 3.42 \\
& $(1.19)$ & $(1.01)$ & $(1.23)$ \\
$\mathrm{H}$ & 6.52 & 3.85 & 4.45 \\
& $(2.12)$ & $(1.71)$ & $(2.31)$ \\
$\mathrm{RP}$ & -3.27 & -2.38 & -2.29 \\
& $(-2.16)$ & $(-1.92)$ & $(-1.86)$ \\
EP & -3.17 & -2.67 & -2.21 \\
& $(-2.11)$ & $(-1.94)$ & $(-1.89)$ \\
L & -3.39 & -2.17 & -3.12 \\
& $(-1.05)$ & $(-0.85)$ & $(-1.02)$ \\
Constant & -11.15 & -8.15 & -10.76 \\
Observations & $(-6.39)$ & $(-4.43)$ & $(-5.29)$ \\
R2 & 90 & 90 & 90 \\
\hline
\end{tabular}

Table 9 Generalized regional "resource curse" in different periods

\begin{tabular}{lcccc}
\hline \multicolumn{1}{c}{ Regions } & $\mathbf{1 9 9 8 - 2 0 0 3}$ & $\mathbf{2 0 0 3 - 2 0 0 8}$ & $\mathbf{2 0 0 9 - 2 0 1 3}$ & RI \\
\hline Yellow river center region & -0.971 & -0.873 & -0.769 & 1.9475 \\
Yangtze River center region & -0.022 & -0.096 & 0.217 & 2.0662 \\
Northeast region & -0.129 & -0.116 & -0.102 & 2.2578 \\
North coastal region & 0.527 & 0.619 & 0.642 & 1.1808 \\
East coastal region & 0.614 & 0.689 & 0.762 & 0.5928 \\
South coastal region & 0.628 & 0.715 & 0.783 & 0.9110 \\
Southwest region & -0.092 & -0.187 & 0.205 & 1.2855 \\
Northwest region & -0.118 & -0.105 & -0.084 & 3.6445 \\
\hline
\end{tabular}


Table 10 Regression results of generalized regional "resource curse" in northeast region of China

\begin{tabular}{cccccccccc}
\hline \multirow{2}{*}{ Variable } & \multicolumn{3}{c}{$\mathbf{1 9 9 8 - 2 0 0 3}$} & \multicolumn{3}{c}{ 2003-2008 } & \multicolumn{3}{c}{$\mathbf{2 0 0 9 - 2 0 1 3}$} \\
\cline { 2 - 10 } & REG & EP & L & REG & EP & L & REG & EP & L \\
\hline \multirow{2}{*}{$\beta_{0}$} & 1.1628 & 1.1637 & 2.0827 & 1.3288 & 1.1644 & 2.3869 & 1.3878 & 1.1685 & 2.5642 \\
& $(0.00)^{*}$ & $(0.00)^{*}$ & $(0.00)^{*}$ & $(0.00)^{*}$ & $(0.00)^{*}$ & $(0.00)^{*}$ & $(0.00)^{*}$ & $(0.00)^{*}$ & $(0.00)^{*}$ \\
& $* *$ & $* *$ & $* *$ & $* *$ & $* *$ & $* *$ & $* *$ & $* *$ & $* *$ \\
$\beta_{1} R$ & -2.3645 & -2.3662 & -5.1842 & -2.7625 & -2.3843 & -6.3247 & -2.9326 & -2.3898 & -6.1934 \\
& $(0.00)^{*}$ & $(0.00)^{*}$ & $(0.00)^{*}$ & $(0.00)^{*}$ & $(0.00)^{*}$ & $(0.00)^{*}$ & $(0.00)^{*}$ & $(0.00)^{*}$ & $(0.00)^{*}$ \\
R2 & $* *$ & $* *$ & $* *$ & $* *$ & $* *$ & $* *$ & $* *$ & $* *$ & $* *$ \\
Waid chi2 & 246.53 & 246.53 & 279.37 & 272.21 & 246.53 & 295.75 & 266.29 & 246.18 & 281.53 \\
Observatio & & & & & & & & & \\
ns & 135 & 135 & 135 & 135 & 135 & 135 & 135 & 135 & 135 \\
\hline
\end{tabular}

Table 11 The impact factors in mechanism of generalized regional "resource curse"

\begin{tabular}{ccccccccccccc}
\hline \multirow{2}{*}{ Variables } & \multicolumn{1}{c}{$\mathbf{1 9 9 8 - 2 0 0 3}$} & \multicolumn{1}{c}{$\mathbf{2 0 0 4 - 2 0 0 8}$} & \multicolumn{4}{c}{$\mathbf{2 0 0 9 - 2 0 1 3}$} \\
\cline { 2 - 13 } & $\beta_{1}$ & $\alpha_{1}$ & $\beta \alpha_{1}$ & Ration & $\beta_{1}$ & $\alpha_{1}$ & $\beta \alpha_{1}$ & Ration & $\beta_{1}$ & $\alpha_{1}$ & $\beta \alpha_{1}$ & Ration \\
\hline REG & -2.3645 & -3.27 & 7.7319 & $23.57 \%$ & -2.7625 & -2.38 & 6.5747 & $24.66 \%$ & -2.9326 & -2.29 & 6.7157 & $21.44 \%$ \\
EP & -2.3662 & -3.17 & 7.5008 & $22.86 \%$ & -2.3843 & -2.67 & 6.3661 & $23.87 \%$ & -2.3898 & -2.21 & 5.2815 & $16.86 \%$ \\
L & -5.1842 & -3.39 & 17.5744 & $53.57 \%$ & -6.3247 & -2.17 & 13.7246 & $51.47 \%$ & -6.1934 & -3.12 & 19.3234 & $61.70 \%$ \\
Total & - & - & - & $100 \%$ & - & - & - & $100 \%$ & - & - & - & $100 \%$ \\
\hline
\end{tabular}

